NBER WORKING PAPER SERIES

\title{
THE EFFECTS OF BUSINESS-TO-BUSINESS E-COMMERCE ON TRANSACTION COSTS
}

\author{
Luis Garicano \\ Steven N. Kaplan \\ Working Paper 8017 \\ http://www.nber.org/papers/w8017 \\ NATIONAL BUREAU OF ECONOMIC RESEARCH \\ 1050 Massachusetts Avenue \\ Cambridge, MA 02138 \\ November 2000
}

This research has been supported by the Kauffman Foundation and the Center For Research in Security Prices. We thank Judy Chevalier, Charles Morris, Rod Parsley, Erik Peterson, Jagadish Turimella, and seminar participants at the NBER E-Commerce project for helpful comments and discussions. The views expressed in this paper are those of the authors and not necessarily those of the National Bureau of Economic Research.

(C) 2000 by Luis Garicano and Steven N. Kaplan. All rights reserved. Short sections of text, not to exceed two paragraphs, may be quoted without explicit permission provided that full credit, including $\odot$ notice, is given to the source. 
The Effects of Business-to-Business E-Commerce on Transaction Costs

Luis Garicano and Steven N. Kaplan

NBER Working Paper No. 8017

November 2000

JEL No. D2, D4, L1

\begin{abstract}
In this paper, we study the changes in transaction costs from the introduction of the Internet in transactions between firms (i.e., business-to-business (B2B) e-commerce). We begin with a conceptual framework to organize the changes in transaction costs that are likely to result when a transaction is transferred from a physical marketplace to an Internet-based one. Following Milgrom and Roberts (1992), we differentiate between the impact on coordination costs and motivation costs. We argue that it is likely that $\mathrm{B} 2 \mathrm{~B}$ e-commerce reduces coordination costs and increases efficiency. We classify these efficiencies into three broad categories - (1) process improvements; (2) marketplace benefits; and (3) indirect improvements. At the same time, B2B e-commerce affects incentive costs. In particular, we discuss the impact of the introduction of e-commerce on informational asymmetries. We implement this framework by analyzing detailed internal data from one Internet-based firm to measure process improvements, marketplace benefits, and motivation costs. We present less detailed data and analyses for one other firm. Our results suggest that process improvements and marketplace benefits are potentially large. We find little evidence that informational asymmetries are more important in the electronic marketplace we study than the existing physical ones.
\end{abstract}

Luis Garicano

Graduate School of Business

The University of Chicago

1101 East $58^{\text {th }}$ Street

Chicago, IL 60637

luis.garicano@gsb.uchicago.edu
Steven N. Kaplan

Graduate School of Business

The University of Chicago

1101 East $58^{\text {th }}$ Street

Chicago, IL 60637

and NBER

steven.kaplan@gsb.uchicago.edu 


\section{Introduction.}

By separating the physical and information flows connected with each transaction, the Internet has provided potentially new ways to trade goods and services. For each individual transaction, the choice between an Internet-based transaction or marketplace and a physical one depends on the transaction costs of each of these two alternatives.

In this paper, we make an early attempt at studying the changes in transaction costs resulting from the introduction of the Internet in transactions between firms. These transactions are more commonly known as business-to-business (B2B) electronic commerce. We begin with a conceptual framework to organize the transaction costs gains and losses that are likely to result when a transaction is transferred from the physical world to the Internet. Following Milgrom and Roberts (1992), we differentiate between the impact on coordination costs and motivation or incentive costs. Concerning coordination costs, we suggest e-commerce produces efficiencies into three broad categories - (1) process improvements; (2) marketplace benefits; and (3) indirect improvements. Concerning motivation costs, we discuss the impact of the introduction of ecommerce on informational asymmetries.

We then discuss how alternative B2B marketplace structures economize differently on transaction costs, and discuss when each model is likely to be most appropriate as a function of the characteristics of the transaction.

Finally, we make use of our framework to estimate the changes in transaction costs that result from $\mathrm{B} 2 \mathrm{~B}$ e-commerce using internal data from two $\mathrm{B} 2 \mathrm{~B}$ e-commerce companies. We are able to estimate these changes in particular detail for one company, Autodaq.com. Because one of the authors is an advisor to these two companies, we use independent external information when we can to confirm the internal information. 
In studying how alternative organizational forms solve the problem of economizing on the costs of transacting, this paper is a descendant of Coase (1939). Our paper, however, takes a substantially different tack from previous empirical literature within this tradition. Previous work has largely been concerned with studying when "the market" should be preferred to "the firm," or occasionally, when each of these should be preferred to different types of long run arrangements. Little work exists, to our knowledge, on the transaction costs of alternative spot market arrangements and on the choice between them.

A second, important difference with previous transaction costs literature concerns the types of transaction costs that we study. Since Joskow's (1985) econometric study of the duration of contracts, the relation between asset specificity and organizational form has been the main concern of empirical work on transaction costs. ${ }^{1}$ We take a broader approach here, studying both incentive or motivation-related transaction costs and those related to coordination problems in different spot market arrangements.

Our approach is also new in its focus on B2B electronic commerce (or e-commerce). Given its recent emergence, there is very little (if any) extant empirical work that studies B2B ecommerce, i.e. commerce in which one business buys from or trades with another business. Most of the early press and academic work on electronic commerce centered on business-toconsumer (B2C) companies like Amazon, AOL, and others. It is possible, however, that the

\footnotetext{
${ }^{1}$ See e.g. Crocker and Masten (1985), for natural gas, and Goldberg and Erickson (1987) in petroleum coke, and Lyons (1994) study of subcontracting in the engineering industry. These papers findings are consistent with the prediction that more specific transactions require longer, more formal contracts. The Lafontaine (1992), Lafontaine and Slade $(1997,1998)$ studies on franchising, on the other hand, have found that specific investments are not very important for franchising, and have studied the determination of royalty rates in these contracts. Finally, Homstrom and Milgrom (1991) find that previous work on the importance of non-selling activities by Anderson (1985) suggest that measurement costs are a key determinant of the extent to which incentive issues matter.
} 
Internet will have a larger impact on $\mathrm{B} 2 \mathrm{~B}$ e-commerce. In particular, B2B e-commerce has the potential to generate substantial efficiencies. ${ }^{2}$

Finally, to our knowledge, our paper is the first one to test for variations in the extent of adverse selection as a consequence of differences in informational asymmetries between markets of different types. Previous tests of 'lemons' models (such as Bond, 1982 or Genesove, 1993) have aimed to obtain evidence of adverse selection in particular markets rather than to understand how different informational conditions in different markets result in different degrees of adverse selection.

The paper proceeds as follows. We being by providing a simple framework to analyze the ways in which B2B e-commerce affects transaction costs. Second, we discuss how alternative B2B e-commerce models (as classified by Kaplan and Sawhney [2000]) economize on transaction costs. Third, we use detailed internal data from Autodaq.com to measure process improvements, marketplace benefits, and motivation costs. We present less detailed data and analyses for one other firm on process improvements and marketplace benefits. Our results suggest that process improvements and marketplace benefits are potentially large. For Autodaq.com, the one company we can study in detail, we do not find evidence of increased motivation costs.

II. A framework for analyzing changes in efficiency due to B2B e-commerce

As mentioned above, B2B e-commerce has the potential to substantially reduce transaction costs in inter-firm trade. Following Milgrom and Roberts (1992), we classify transaction costs in two categories: costs associated with the problem of coordination and costs

\footnotetext{
${ }^{2}$ E.g., see Sawhney and Kaplan (1999).
} 
associated with the problem of motivation. Shifting a transaction from a physical environment to the Internet has the potential to affects both types of transaction costs.

\section{A. Coordination costs}

Coordination costs are "related to the need to determine prices and other details of the transaction, to make the existence and location of potential buyers and sellers known to one another, and to bring the buyers and sellers together to transact." ${ }^{33}$ We find it useful to classify the effects of the Internet on coordination costs into two general categories: process improvements and marketplace benefits. Below, we describe the potential Internet-based improvements in these coordination costs. It is important to recognize (and we then discuss) that reductions in transactions costs are likely to lead to additional direct and indirect benefits. We use this framework in later sections to study the gains attained in some examples.

\section{Process improvements}

B2B e-commerce can improve efficiencies by reducing the costs involved in an existing business process. Such an improvement may take place in two basic forms. First, it may simply reduce the cost of an activity already being conducted, as when a transaction that is currently conducted by phone or fax is automated. In other instances, the Internet provides an opportunity to redesign the existing process. ${ }^{4}$

The methodology we use to measure or estimate the value of process improvements is straightforward. First, we describe and measure the costs of the activities involved in the

\footnotetext{
${ }^{3}$ Milgrom and Roberts (1992), p. 28.

${ }^{4}$ See Kaplan and Sawhney (2000). They also provide a summary description of Autodaq.com which we describe in more detail below.
} 
existing process in detail. Second, we describe and measure the costs of the process using B2B e-commerce. The difference, if any, is the value of the process improvement.

\section{2. $\quad$ Marketplace benefits}

We classify the second way in which B2B e-commerce can reduce coordination costs as marketplace benefits (or direct information improvements). These benefits come in some of the following forms. ${ }^{5}$ The Internet potentially reduces a buyer's cost of finding suppliers because it is less expensive to search for products and compare prices over the Internet than it is to read catalogs and make phone calls. Conversely, sellers can reach more potential customers at lower cost. As a result, buyers will find sellers they might not have otherwise found. EBay is an example of this on the consumer side. (eBay is $\mathrm{C} 2 \mathrm{C}$ - consumer-to-consumer.)

Second, the Internet potentially provides buyers with better information about product characteristics (including prices and availability) because it is less expensive to obtain.

Finally, the Internet also potentially provides better information about buyers and sellers.

On the other hand, conducting the transaction over the Internet may increase these transaction costs, due to the buyers' inability to physically inspect the merchandise object of the exchange. This may be the case when buyers need to match their needs for objects based precisely on a characteristic that requires physical inspection. For example, consider the second hand car example that we explore in depth later. Suppose that dealers in a particular location sell cars to a lower income, older consumer who takes good care of the cars, while dealers in another location cater to lower income handy-men. Holding all the observable characteristics constant, dealers in the first location will be looking for cars in perfect condition; while dealers in the

\footnotetext{
${ }^{5}$ Also, see Phillips and Meeker (2000).
} 
second location will be looking for cars in bad, but repairable condition. If the condition of the car is hard to communicate without hearing the motor and looking at the car, it will be difficult to distinguish between these cars in an Internet auction. As a consequence, the matching of cars with buyers may be worsened. It is important to note that this effect takes place regardless of the fact that the composition of supply of cars is unchanged (no adverse selection).

Estimating these costs and benefits is appreciably more difficult than estimating the process improvement benefits. One place to look - and one for which we have data - is at the buyer's willingness to pay for each object. Higher willingness to pay by buyers for a particular item is evidence of better matching. Other places to look include the amount of trade and prices sellers receive. If $\mathrm{B} 2 \mathrm{~B}$ e-commerce delivers marketplace benefits, trade should increase. Ebay is a clear example of this in that trade occurs that would not occur otherwise. Higher prices for sellers would represent better matching. It is likely, on the other hand, that lower customer acquisition costs would reduce prices.

\section{Direct and indirect effects of coordination costs reductions}

Clearly, any reduction in coordination costs results in direct economic gains through a reduction in the cost of undertaking these transactions. It is possible, however, that other indirect benefit also will arise. As the costs of undertaking spot market transactions decreases, participants in these transactions may adjust their behavior and realize further efficiency gains. Although estimating these effects is beyond the scope of this paper, we discuss briefly here the effects of the two main sources of these changes: better information processing, and changes in organizational form. 
Better information about future demand through B2B e-commerce may allow a seller to improve its demand forecasts, and use that information to change its production decisions to better match demand. Conversely, a buyer might obtain better information about existing (and future supply), and use that information to change its inventory decisions.

Second, make or buy decisions are likely to be affected. If the Internet is able to produce important decreases in the costs of carrying out transactions in the market, the transaction costs economizing paradigm (Coase [1939] and Williamson [1985]) leads us to predict that fewer transactions will be undertaken inside firms and more will be undertaken in the market.

\section{B. $\quad$ Motivation costs}

Milgrom and Roberts (1992) distinguish two types of motivation-related transaction costs: those associated with informational incompleteness and asymmetries, and those associated with imperfect commitment.

\section{Informational incompleteness and asymmetries}

These type of transaction costs are present "when the parties to the transaction do not have all the relevant information needed to determine whether the terms of an agreement are acceptable and whether they are actually being met." the merchandise to evaluate its condition is valuable to the buyer, some of that information is lost through the conduct of the transaction through an electronic format.

This loss of information about the object of the exchange may translate into an efficiency loss if adverse selection worsens in virtual transactions. Consider, for example, the original lemons issue in second hand automobile markets (Akerlof, 1970), which will later be our 
example. Holding observable characteristics constant, sellers might try to sell cars with strange sounding motors exclusively thorough the Internet. ${ }^{7}$ If sellers offer this type of object more frequently over the Internet, buyers willingness to pay for the average object decreases, leading sellers of higher (unobserved) quality to withdraw from the market.

\section{Transaction costs that arise from imperfect commitment}

Milgrom and Roberts (1992) define these costs as deriving from "the inability of parties to bind themselves to follow through on threats and promises that they would like to make but which, having made, they would like to renounce." B2B e-commerce has the potential to increase or decrease these costs. First, by standardizing processes and by leaving an electronic trail, the Internet has the potential to reduce the costs of imperfect commitment. Alternatively, a buyer may avoid intermediary fees by viewing the product over the Internet, but contacting the seller directly.

\section{Alternative B2B e-commerce hubs and transactions costs}

B2B e-commerce companies and intermediaries are structured in a number of different ways. These different intermediary and transaction structures, in turn, have different effects on transaction costs. Again, as with the choice between physical and electronic transactions, the choice of electronic transaction structure is likely to depend on the attributes of the transactions. In what follows, we refer to B2B intermediaries as hubs because they perform functions other than just pure marketplace functions.

\footnotetext{
${ }^{6}$ Milgrom and Roberts (1992).

${ }^{7}$ Thrid-party inspections can eliminate this problem.
} 
In terms of their effect on transactions costs, hubs can be classified ${ }^{8}$ by (1) the nature of prices and terms; and (2) the bias of the marketmaker. We discuss the effect of these different structures on transaction costs, and which structure is likely to be superior in different circumstances.

\section{A. $\quad$ Nature of prices and terms}

Prices and terms of transactions in B2B hubs take two basic forms - fixed pricing or dynamic pricing. ${ }^{9}$ In the first case, which is essentially an on-line version of a catalog, the value of the Internet is that it allows the aggregation of a large number of buyers and sellers under one roof, and reduces transaction costs by "one-stop shopping." For instance, Chemdex.com allows laboratories or hospitals to issue a single purchase order for hundreds of life science products, and Chemdex.com sources these products from a diverse set of suppliers. The aggregation mechanism is static in nature, because prices are pre-negotiated. The aggregation mechanism (also called the "catalog mechanism") is likely to work best for small or low value transactions where negotiation is cost prohibitive. This can occur for a number of reasons such as a very high number of SKUs (Stock Keeping Units), a highly fragmented supplier universe, a high cost of processing a purchase order relative to the cost of items procured.

In the second type of transaction, prices and terms are not fixed. The hub uses a matching mechanism that creates value by bringing buyers and sellers together to negotiate prices and terms on a dynamic and real-time basis. For example, Autodaq.com brings buyers and sellers of used cars together; Altra Energy makes a market in energy and electricity. The source of value creation in the matching mechanism is improved matching due to improved

\footnotetext{
${ }^{8}$ In this section, we rely on and expand on Kaplan and Sawhney (2000).

${ }^{9}$ It is important to point out that a particular marketplace may undertake both types of transactions.
} 
marketplace liquidity. While catalogs benefit only from the aggregation mechanism, exchanges benefit from both aggregation and matching. The matching mechanism tends to work best for when the value of the transaction is high and negotiation cost is not prohibitive. This is more likely when products can be fully and reliably described on-line and traded sight-unseen.

\section{B. Biased versus neutral hubs}

Another dimension that is important in describing a B2B hub is its bias. B2B hubs can be either neutral or biased. Neutral hubs do not favor buyers over sellers or vice versa. Biased ones, in contrast, favor either buyers or sellers. As a result, neutral hubs are faced with a "chicken-and-egg" problem, in that they need to get buyers as well as suppliers into their system, without compromising their neutrality. They need to be careful in taking equity investments from large buyers as well as from large suppliers, because they can be perceived as biased. The benefit that neutral hubs have is that they are true "market-makers", because they bring both buyers and sellers together.

Some hubs are one-sided and biased by design. These biased hubs work either for the sellers or the buyers, and help them to negotiate better terms or streamline the buying/selling process. Biased hubs (like neutral hubs) can operate both as aggregators and as matchers. When they favor sellers, biased hubs act as forward aggregators or forward auctioneers. When they favor buyers, biased hubs act as reverse aggregators or reverse auctioneers.

\section{Sample companies}

We analyze detailed data provided by Autodaq, a B2B e-commerce company. We recognize that because the data are provided by Autodaq, they are potentially biased. As 
mentioned earlier, one of the authors is an advisor to Autodaq.com. We address these potential biases by buttressing the Autodaq data with data provided by competitors. The evidence from Autodaq and from the competitors is consistent. We also present and discuss less detailed data provided by one other B2B company, NutraBid.

\section{Autodaq}

Autodaq operates in the wholesale used car auction market for large volume sellers such as rental companies, lease finance companies, commercial fleets and manufacturers. The buyers in this market are automobile dealers, not individuals. Rental companies buy new cars, rent them for several years, and then sell them. Lease finance companies lease new cars for several year terms. At the end of the lease term, roughly half of the cars are either purchased by the lessee or by the original dealer. The lease finance company must sell the cars that are not purchased by the lessee or the dealer. In 1999, the wholesale used car auction market included roughly 1.4 million cars from rental companies, 1.9 million cars from lease finance companies, and 2.1 million cars from commercial fleets. ${ }^{10}$ The wholesale used car auction market, therefore, is roughly 5 million cars per year.

\section{A. $\quad$ Process improvements}

We compare the time and economic costs involved in the Autodaq / Internet process with those in the physical auction process.

In the physical world, when a large volume seller needs to dispose of a car, the seller stores the car, then has it transported to a physical auction site. At the physical auction site, the

\footnotetext{
${ }^{10}$ See the "2000 Used Car Market Report," produced by ADT Automotive, the number two player in physical auctions.
} 
car is described and inspected. The car also may be reconditioned by the auction site operator. Reconditioning involves repairing minor flaws in the car's exterior - dents, scratches, cracked windows, etc. Dealers travel to the physical auction site and bid on the car. After the auction, the dealers go home and the car is transported again to the winning dealer. The winning dealer performs any necessary maintenance or repairs on the car and any necessary additional reconditioning.

In the Autodaq / Internet system, Autodaq contracts with an inspector who inspects, describes, and photographs the car. For cars coming off lease, this occurs at the dealer from whom the lessee leased the car. For cars coming from fleets, this occurs at the fleet holding lot. The car is then put up for sale in an online auction. Dealers bid on the car over the Internet from their computers. The car is transported to the winning dealer. The winning dealer performs any necessary maintenance or repairs on the car and any necessary reconditioning. If the car does not sell over the Internet, the seller can decide to engage the physical auction process. ${ }^{11}$

Unlike in the physical auctions which are exclusively run as ascending oral auction, the Autodaq auctions employs a variant of a second price auction in the form of a "proxy bidding" mechanism, in which dealers submit the highest price they would be willing to pay, and Autodaq automatically increases their bid in the presence of other bids by just enough to become the leading bid. The auction format also allows dealers to directly purchase the car by accepting the ask price given by the seller.

Table 1 compares the physical auction process to the Autodaq Internet process, both in terms of time and money. The comparison is made for a typical car coming off lease or from a

\footnotetext{
${ }^{11}$ This process is not unique to Autodaq. Several competitors exist. In particular, the largest operator of physical auctions, Manheim, has an Internet based subsidiary - Manheim Online. Manheim Online differs from Autodaq in that it uses the Internet to list the cars that it has for sale at its physical auction site. In its current incarnation, therefore, Manheim Online, potentially reduces buyer transaction costs, but does not change seller transaction costs.
} 
rental fleet. The table measures time from the day the car comes off lease or is retired by the rental car company to the day the car arrives at the buying dealer. The table measures costs as the economic costs of the process. It does not measure the benefits to a seller from moving from a physical process to the Internet process.

In panel A of table 1, we report the estimated time involved in the physical auction process, i.e., the time that elapses from the day a car comes off lease or out of a fleet to the day the car is delivered to the purchasing dealer. The estimates in panel A were provided by Tom Kontos of ADT Automotive. As mentioned earlier, ADT Automotive was the second largest competitor in the physical auction business. ${ }^{12}$ We obtained similar estimates in interviews with other industry participants. Panel A reports that the physical auction process takes from 28 to 44 days.

One of the lessors that provided Autodaq cars to sell also provided Autodaq with information on cars the lessor sold through the physical auction process. With that information, we were able to calculate two separate times. For all 9,205 cars, we calculate the time that elapsed from the day a car was inspected by the lessor to the day the car was sold. The median time is 35 days. We add two days to this to estimate the time until the car is delivered to the purchasing dealer. Panel B of table 1 reports that the median elapsed time is 37 days. This is close to the midpoint of the range provided by ADT Automotive. 37 days also is completely consistent with the estimates we obtained from other interviews.

For 7,221 cars, we can measure the time from lease end to sale. This measure is problematic in our sample because a number of cars are sold well before the lease end date. It also seems as if a number of cars are put up for sale well after the lease end date. Nevertheless, we calculate the median time from lease end to sale in our sample as 36 days (compared to 35 
days from inspection). In our analysis in table 1, we use the time from inspection to sale because (1) it appears to be a more reliable measure of the disposition process and (2) we have inspection dates for all cars, but do not have lease dates for all cars.

Panel C of table 1 reports Autodaq's estimates of the time that is involved in the Internet auction process. Autodaq believes that the Internet process should take 7 days rather than the 37 days in the physical auction process.

The savings in time come in several areas. First, it typically takes 9 to 15 days before lessors and fleet owners ship cars to the physical auction site. Part of the reason for the delay is that the physical auction company does not pick the car up immediately. The other reason is that the seller may attempt to sell the car to the original dealer, but must take some time attempting to determine the appropriate price. It is not entirely clear that all of the savings here are Internet specific. It would seem possible for the lessors to contract with a physical auction site to reduce this time as well. It remains to be seen whether Autodaq can reduce this time.

Second, it typically takes 15 to 25 days from the time a car arrives at a physical auction site until it is sold. On the Internet, Autodaq estimates this time can be reduced to 4 days. One reason for the delay in the physical auction process is that the car generally waits some time before it is reconditioned and reconditioning takes some time. ${ }^{13}$ The most important reason, however, is that the physical auction sites try to make each individual auction somewhat homogeneous in terms of the cars available. In other words, sell largely Fords in one auction; largely Toyotas in the next. This makes sense because dealers typically look for particular types of cars. As a result, the physical auctions will wait until they have a critical mass of a particular

\footnotetext{
${ }^{12}$ ADT has subsequently merged with Mannheim, the largest competitor in the physical auction business.

${ }^{13}$ It is important to note that in both the Autodaq system and the physical auction, buying dealers typically perform reconditioning. In the case of the physical auction, this is despite the fact that the physical auction already did some
} 
car type before holding an auction. This is not a consideration for Autodaq because the dealer does not have to physically go to the Autodaq auction site, but simply log in.

Autodaq's estimates make two optimistic assumptions. First, the estimates assume that the cars sell quickly on the Internet, which implies a liquid market. Second, the estimates assume that the cars are listed for sale almost immediately after they come off lease which assumes sophisticated and timely tracking and inspection processes. We interpret Autodaq's estimates, therefore, as the likely process costs of a liquid Internet market.

In Autodaq's initial markets, it is not likely that the Internet was completely liquid. We were able to calculate the actual time that elapsed from the day a car was inspected by the lessor to the day the car was sold for 694 cars sold over the Internet by Autodaq. The median time is 14 days. ${ }^{14}$ We add three days to this to estimate the time until the car is delivered to the purchasing dealer. Panel D of table 1 reports that the median elapsed time is 17 days.

The "Dollars" columns in table 1 attempt to value the economic costs of the two processes. The most important costs are the costs of capital, depreciation, and transportation. The cost of capital is relatively straightforward. The typical car (in our sample) sells for $\$ 13,600$. Each day the car is not sold, the seller is not able to deploy that capital elsewhere. We assume a cost of capital of $8 \%$. This is essentially a debt cost of capital which may understate the true cost of capital for a seller.

The cost of depreciation is based on the fact that sale prices for used cars depreciate with the age of the car. Autodaq estimates that the sales price depreciates by $12 \%$ each year. In the data provided by Autodaq, the sales price actually declines by $14.8 \%$ (with a standard error of $1.7 \%)$. To be conservative, we use $12 \%$ in our analysis.

reconditioning work. It is possible that the reconditioning time is greater in the Autodaq system, although Autodaq claims that this is not the case. 
Autodaq and the industry experts we spoke to estimated that it cost $\$ 110$ to ship a car from the lessor to a physical auction and then an additional $\$ 110$ to ship a car from the physical auction to the buyer. The transportation cost to ship a car from the lessor directly to a local buyer was estimated at $\$ 137$. The difference presumably reflects the absence of economies of scale in shipping directly.

Autodaq estimates that a dealer travels one hour each way to the auction and buys four cars at the auction. This translates to one-half hour of travel time per car. Conservatively valuing the dealer's time at $\$ 40$ per hour, this translates into $\$ 20$ per car. Autodaq assumes that the dealer spends five hours at the physical auction. We assume, conservatively, that the dealer does not waste any of these five hours at the auction.

Finally, we assume that reconditioning costs are the same for the physical auction as for the Internet auction. This also is likely to be conservative in that cars bought in a physical auction are usually reconditioned again by the buyer after they are bought. To account for this, we have not added any extra time to the Internet process for reconditioning.

Based on these assumptions, we estimate that the physical auction process has an economic cost of \$520 per car (not including reconditioning). The Autodaq / Internet process under the assumption of a liquid market has an analogous economic cost of only $\$ 249$ per car - a \$271 reduction. The actual results for the 694 cars sold using the Autodaq / Internet process imply an economic cost of \$324 per car - a \$196 reduction.

It is important to note that both Internet estimates are conditional on cars being sold. If the Internet market becomes liquid and as the probability of an Internet sale becomes one, then the estimates of process savings become unconditional estimates as well.

\footnotetext{
14 The median time from lease end to sale is 20 days for 270 cars.
} 
In the sample Autodaq provided us, the probability of a sale was $24 \%$ not $100 \%$. As a result, the (conditional) process savings overstate the actual savings. We can estimate the actual savings using the following assumptions. The lessor attempts to sell a car over the Internet. If a sale occurs, it occurs in a median 15 days. In the $76 \%$ of cases in which a sale did not occur, the lessor decides after 15 days to sell the car through a physical auction process. The car then takes (the sample median) or 37 days before it is delivered to a purchasing dealer. ${ }^{15}$ For these cars, the lessor incurs 15 additional days of interest and depreciation costs that we estimate to be $\$ 112$. In our sample, relative to the physical auction process, the Autodaq / Internet process provides a $24 \%$ likelihood of a $\$ 196$ reduction in process costs at a $76 \%$ likelihood of a $\$ 112$ increase in process costs. The net effect is an average increase in process costs of $\$ 38$ per car.

This analysis highlights that liquidity is important in an Internet market not only to deliver attractive pricing, but also to deliver savings in process costs.

Overall, the results in table 1 indicate potentially substantial reductions in process costs for cars sold using the Internet. These reductions will be realized if the Internet market becomes more liquid. Not including reconditioning, the reductions in a liquid market are on the order of $38 \%$ to $52 \%$ of the total economic cost. Multiplied over an annual market of 5 million cars, the analysis implies potential process cost reductions on the order of $\$ 1$ billion per year.

\section{B. $\quad$ Marketplace Benefits}

As we argued above, an important potential benefit of B2B is the extension of the market it provides. Both buyers and sellers can search a larger number of counterparts, and as a consequence may find goods and services that they would not otherwise have found. In the case

\footnotetext{
${ }^{15}$ The assumption of 37 days probably overstates the amount of time it would take. Because the car is already identified and in the Internet process, it should not have to wait for 9 to 15 days to be picked up.
} 
of used automobiles, this is a clear advantage. Used automobile dealers require an appropriate mix of inventory in their dealerships. Obtaining that mix is the main reason they purchase at auctions.

Estimating marketplace benefits presents important challenges. The aim of the estimation in Autodaq's case is to assess how much more a dealer would be willing to pay in the Internet market (versus the physical market) for a car that better matches the dealer's desired inventory. Clearly, this is a fundamentally unobservable quantity. On the other hand, the extended size and reach of the marketplace is potentially one of the main benefits of the Internet, and getting some grasp on the magnitude of this gain is important.

In what follows, we propose a simple method that exploits (1) the geographic rollout used by Autodaq and (2) a no-arbitrage argument on the seller side. Under reasonable conditions, this estimate allows us to place a lower bound on the dealer's willingness to pay for the added convenience of the larger marketplace.

Autodaq's rollout followed a predetermined pattern. Between the end of October of 1999 and the end of February 2000, the buyers of automobiles were almost exclusively in California. The sellers, on the other hand, were three large leasing companies that sold cars coming off lease throughout the US. Cars sold in California in that period, therefore, included cars from the South, Midwest and West regions of the U.S.

The type of sellers implies that the cars were, from their perspective, commodities up to their physical characteristics. In this analysis, we assume that adverse selection problems are absent. $^{16}$

The willingness to pay by buyers for each car differs widely, as it depends on the quality of the match of the particular car with the needs of the dealership. We model here this 
willingness to pay explicitly in the simplest way possible to obtain practical way to estimate the value of a better match.

Suppose that the quality of the match is given by a function $\mathrm{V}$ of the distance in the characteristics space between the car sought $\mathrm{x}^{*}$ and the car on offer at that point $\mathrm{x}, \mathrm{V}\left(\mathrm{x}^{*}-\mathrm{x}\right)$, with $\mathrm{V}^{\prime}<0$, meaning that the revenue that a dealer will obtain is larger the smaller is this distance between ideal car and car in hand. Then the profit of a dealer who purchases a car $x$ is given by the value of this match minus its total cost, i.e.

$$
\pi=V\left(x^{*}-x\right)-p(x)-T(x)-C_{B}
$$

where $p(x)$ is the price of a car with characteristics $x, T(x)$ is the transport costs of this car, and $C_{B}$ is the processing cost of purchasing the car (the process transaction cost we analyzed above).

Suppose now that a dealer has a choice between two cars which are, from the perspective of the seller, identical, but that, given the needs of the dealer, have different value to him, since one is closer in the characteristics space to his needs. Suppose, first, that both of these cars can be purchased over the internet, but one is geographically further away. Given our application, consider that one car can be bought in California, where the dealership is, and the other out of state. The profitability of this purchase will be, for the California car with characteristics $x_{C A}$ :

$$
\pi_{C A}=V\left(x^{*}-x_{C A}\right)-p\left(x_{C A}\right)-T\left(x_{C A}\right)-C_{B}^{I}
$$

where $C_{B}^{I}$ is the internet transaction or processing cost; and for the out of state car, with characteristics $x_{N C A}$ :

$$
\pi_{N C A}=V\left(x^{*}-x_{N C A}\right)-p\left(x_{N C A}\right)-T\left(x_{N C A}\right)-C_{B}^{I}
$$

If the dealer purchases the car that requires longer distance transport, then

\footnotetext{
${ }^{16}$ Our analysis below in section V.C suggests that adverse selection is not an issue here.
} 


$$
\pi_{N C A} \geq \pi_{C A}
$$

which implies that

$$
V\left(x^{*}-x_{N C A}\right)-p\left(x_{N C A}\right)-T\left(x_{N C A}\right)-C_{B}^{I} \geq V\left(x^{*}-x_{C A}\right)-p\left(x_{C A}\right)-T\left(x_{C A}\right)-C_{B}^{I}
$$

Since the two cars are from the perspective of the seller, identical, we can assume $p\left(x_{N C A}\right)=$ $p\left(x_{C A}\right)$. Then the difference in the valuation of the two matches is bounded from below by the difference in the transport costs:

$$
V\left(x^{*}-x_{N C A}\right)-V\left(x^{*}-x_{C A}\right) \geq T\left(x_{N C A}\right)-T\left(x_{C A}\right)
$$

In words, if we observe that a dealer buys a car that is not from California, the dealer must have viewed that car as a particularly attractive match in order to incur the additional transportation costs. From a seller perspective, we assume that the cars are indistinguishable. The difference in transportation costs, therefore, provides a lower bound estimate of the difference in willingness-to-pay for cars that are purchased from out-of-state. This provides an estimate of the marketplace benefit for those cars.

In table 2, we report the transportation costs for 586 cars sold in the Autodaq Internet auction. The transportation costs are the actual costs paid by the buyers. Table 2 shows that transportation costs average $\$ 465$ for out-of-state cars and only $\$ 223$ for California cars, implying a transportation cost differential of $\$ 242$ per car.

It is important to note, that we cannot say with certainty how much value was created from this improved matching in our sample. In the extreme, it is possible that the buyer values an out-of-state car at exactly $\$ 242$ more than an in-state car and pays the entire differential in transportation costs, leaving the buyer with no surplus. It is possible to say, however, that with a liquid Internet market, dealers in California will be able to buy cars in California over the Internet and capture more, if not all, of the gains from improved matching. 
We also can attempt to estimate the marketplace benefits relative to a physical auction. Call the physical auction market price of a particular car, $p\left(x_{P}\right)$, the Internet price, $p\left(x_{I}\right)$, and the excess process costs of the physical auction over the Internet for the seller, $\mathrm{C}_{\mathrm{s}}$. For a sale to take place on the Internet, the Internet price must be at least equal to the physical auction price less the process costs:

$$
p\left(x_{I}\right) \geq p\left(x_{P}\right)-\mathrm{C}_{\mathrm{S}}
$$

As before, the value of a particular match by a dealer who purchased in the internet is given by:

$$
\pi_{I}=V\left(x^{*}-x_{I}\right)-p\left(x_{I}\right)-T\left(x_{I}\right)-C^{I} \mathrm{~B}
$$

While, calling CPB the processing transaction cost for the buyer in a physical market, the value of an identical car (from the perspective of the seller) in a physical market is:

$$
\left(P=V\left(x^{*}-x P\right)-p(x P)-T(x P)-C P B\right.
$$

As previously, if a dealer chose to purchase over the internet, it must be true that ( $\mathrm{I}>(\mathrm{P}$. , i.e.

$$
\mathrm{V}\left(\mathrm{x}^{*}-\mathrm{xI}\right)-\mathrm{p}(\mathrm{xI})-\mathrm{T}(\mathrm{xI})-\mathrm{CIB}\left(\mathrm{V}\left(\mathrm{x}^{*}-\mathrm{xP}\right)-\mathrm{p}(\mathrm{xP})-\mathrm{T}(\mathrm{xP})-\mathrm{CPB}\right.
$$

Calling the cost savings due to the internet for the buyers $\mathrm{CB}=\mathrm{CPB}-\mathrm{CIB}$, substituting the inequality $\mathrm{p}(\mathrm{xI})$ $(\mathrm{p}(\mathrm{xP})-\mathrm{CS}$ and rearranging, we have

$$
\mathrm{V}\left(\mathrm{x}^{*}-\mathrm{xI}\right)-\mathrm{V}\left(\mathrm{x}^{*}-\mathrm{xP}\right)+\mathrm{CB}+\mathrm{CS}((\mathrm{TI}-\mathrm{TP})
$$

This allows us to say that the sum of the marketplace benefits and the process improvements is at least equal to the difference in transportation costs caused by the additional shipping distance of the Internet auction versus the physical auction. As before, it may be the case that, at the current stage of development of the internet, the total increase in surplus is small, if the transport costs are equal to the efficiency gains. But we can be certain that, as the internet market gets more liquid, more and more of these transport costs will be eliminated, and the entire left hand side term will be an efficiency gain. 
In our sample, we can estimate differential transportation costs caused by the additional shipping distance. Autodaq and industry analysts we spoke to estimated that the buyer pays roughly $\$ 110$ to transport a car it buys from a physical auction site to its dealership. As we reported above, table 2 shows that average transportation costs are $\$ 465$ for cars transported from out of state to dealers in California. This suggests that the average car from out-of-state purchased on the Internet is transported a much greater distance than the average car purchased at a physical auction. The extra transportation cost of $\$ 355$ suggests that the sum of the marketplace benefit and process cost reductions exceeded $\$ 355$ on average for out-of-state cars sold on the Internet. Again, in a more liquid market, presumably the distance required to obtain improved matching will decline and more of the benefit will accrue to buyers and sellers. ${ }^{17}$

In summary, these results suggest substantial marketplace benefits to the Internet auction in the wholesale used car market. These benefits are potentially of the same order of magnitude as the process improvements.

\section{Asymmetric Information in Physical and Internet Automobile Auctions}

While in a physical auction a buyer has an independent indication of the condition of the car, in the form of his own evaluation, the Internet auction relies exclusively on hard, quantifiable data that can be observed in the database. As a consequence, informational asymmetries between sellers and buyers may be more pronounced in Internet auctions.

The potential informational loss may be small, however, as information in physical auctions is usually restricted. In a description of these physical auctions, Genesove (1993) points out the limited access to the cars enjoyed by the bidders:

\footnotetext{
17 This calculation also is conditional on an interstate sale.
} 
"Prior to the bidding, the car is parked outside, where potential bidders can examine its exterior. they are prohibited from opening the doors or raising the hood. Mileage and options are chalked on the car's windows. When the car's turn approaches, it is driven into the appropriate lane and then, before bidding is concluded on the previous car, driven up to the auction block. Now the hood is raised and dealers are permitted to enter the car. There is time to check the odometer, to ensure that the air conditioner works (but, in the summer months at least, not the heater) and to take a look at the running motor. But there is no opportunity to test the brakes or any number of other things that a consumer might check out in a drive around the block (...)

On top of the auction block stands the auctioneer and, beside him, the seller, who under the rules of the auction must be present. The auctioneer announces any major defects in the car, of which the seller has informed him. Bidding is oral and ascending. When bidding will go no higher, the seller is asked to accept or reject the winning bid. About $60 \%$ of the time he accepts. The car will have been driven away before the bidding is concluded. Form the time it arrived at the auction block until the time it is driven away, a minute and a half will have passed."

Internet-based auctions such as those run by Autodaq, on the other hand, do not allow any physical inspection of the cars by the buyer. ${ }^{18}$ Instead, the seller and the Autodaq inspection provide an extensive list of information on the car's options and on all other measurable aspects of the car condition, such as its mileage, the damages suffered, age etc. Importantly, Autodaq does not preclude buyers and sellers from participating in physical auctions. This raises the possibility of sellers offering only those cars that are in a relatively worse unobservable condition through this channel.

Possibly attenuating adverse selection in our data is the fact that Autodaq is primarily directed at lessors and fleet owners. Individual used car dealers have only recently started selling cars. Only 571 out of 3552 cars auctioned, and 111 out of 864 cars sold where auctioned by a dealership.

To understand the implications of the coexistence of these two markets, we take as our starting point a variant of the simple model of adverse selection of Akerlof (1970). Suppose that, conditional on all the observable characteristics, there are two types of cars, G (good) valued by

\footnotetext{
${ }^{18}$ Both Autodaq and the physical auctions do inspect the cars and describe them for buyers. Autodaq argues (and we agree), that the information in electronic form is richer and more useful as it allows buyers to search more efficiently for their desired cars and options.
} 
consumers at $\mathrm{P}_{\mathrm{G}}$ and lemons $\mathrm{L}$, valued at $\mathrm{P}_{\mathrm{L}}$ with the proportion of good cars sold in a particular market given by $q .^{19}$

First, consider the physical market. Suppose that there exists no asymmetric information in the physical market, so that good cars can be sold at price $\mathrm{P}_{\mathrm{G}}$ and lemons at price $\mathrm{P}_{\mathrm{L}}$ in that market. Suppose the higher cost of the physical market mechanism is $C$, so that the value of the sale to the seller is $\mathrm{P}_{\mathrm{G}}-C$ if the car is not a lemon, $\mathrm{P}_{\mathrm{L}}-\mathrm{C}$ if it is. The average price of cars sold in the physical market is

$$
P_{p}=q P_{G}+(1-q) P_{L}
$$

Now consider that a competitive electronic market also exists. Here, both classes of cars cannot be distinguished, as consumers cannot physically inspect the cars. There exist two types of outcomes in this market, depending on the cost of the informational asymmetries relative to the benefit of using an electronic market medium:

1) When the cost of the physical market mechanism is high enough relative to the asymmetric information costs, so that the average price is higher than the net profit from selling a known good car in the physical market, i.e. if

$$
\begin{gathered}
q P_{G}+(1-q) P_{L}>\left(P_{G}-C\right) \text { or, equivalently. } \\
C>(1-q)\left(P_{G}-P_{L}\right)
\end{gathered}
$$

both types of cars are sold in the electronic market, at a price $P_{e}=\mathrm{q} \mathrm{P}_{\mathrm{G}}+(1-\mathrm{q}) \mathrm{P}_{\mathrm{L}}$. In this case, the ratio of average physical market price to electronic market price is 1 .

2) If the cost imposed by the presence of lemons on the sellers of good cars is higher than the gain from using an electronic market $C$, or formally if

$$
C<(1-q)\left(P_{G}-P_{L}\right)
$$

\footnotetext{
${ }^{19}$ Consistent with our previous discussion, the entire surplus is captured by the seller. We now ignore the transport costs considerations to simplify the discussion.
} 
no transactions of good cars take place, as good cars are withdrawn and sold in the physical market. In this case adverse selection exists in the electronic market. The observed average market price, reflecting the lower average quality of cars transacted, is $P_{e}=L$.

Adverse selection translates in this case in the withdrawal from the electronic market of cars with relatively good unobservable characteristics within each class from the electronic auction in favor of the physical world auction. As a consequence, we can expect in these circumstances lower average price, conditional on observable characteristics, for cars sold over the Internet. High quality cars for each level of observable characteristics would have a low probability of being sold, ${ }^{20}$ given that the seller would demand high average prices for the average condition that buyers expect to find in the market.

Apart from this implication for relative price levels, adverse selection also has implications on the price structure. If adverse selection is important, Internet prices must be lower relative to physical world prices when the risk of adverse selection is larger. When a low risk of adverse selection exists, i.e. when the variance in the condition of cars is small, the difference between the physical world and the Internet prices must be small. On the other hand, when the risk of adverse selection is high, this spread must be large. This different risk is to a large extent predictable. The variance in the unobservable condition of the car is largely a consequence of the unobservable care by the owner. Thus the more that the quality of care affects the value of the car, the larger the risk of adverse selection. ${ }^{21}$

\footnotetext{
${ }^{20}$ Note that the seller could just not bring high quality cars to the auction block. Given that the cost of just posting the car on the electronic market is very low, and that the reservation price can be used to avoid selling it cheap, we can expect even cars with very good unobservable characteristics to be posted. In fact, we know that the sellers in the programs under study posted all their cars.

${ }^{21}$ There is another type of adverse selection in this market, unrelated to the quality of care, but caused by the manufacturing quality of the car. We think this is unlikely to be an issue here for two reasons: first, those initial defects are infrequent; and, second, all the models are less than 4 years old and manufacturer warranties typically cover manufacturing defects.
} 
Genesove's (1993) study of adverse selection in used car markets is the most notable precedent for our research. He tests for adverse selection by analyzing the effects of the identity of the seller on prices. He expects systematic differences between the incentives of used and new car dealers to sell used cars to show up in differences in prices if they are selling different quality cars. Our study differs from his in that, rather than examining adverse selection in one market, our focus is on comparing adverse selection in two different markets where we expect, a priori, to find different degrees of informational asymmetry in them. However, we rely on Genesove's insights to examine the extent of adverse selection in the internet market in itself.

\section{Data}

Our sample is formed by 3552 sold and unsold cars on auction at Autodaq.com throughout the first nine months of 2000 . These are all of the cars that were on auction by Autodaq at least once, except for those that were withdrawn by their owners without completing a three-auction cycle. ${ }^{22}$ Throughout most of the time in our sample, all cars were put through a maximum of three auction cycles ${ }^{23}$.

The construction and content of most of the variables in our sample is self-explanatory. One exception is the ratio of Internet to physical price, which aims to proxy the counterfactual world of "how much would people have been willing to pay for this car on the physical world." We constructed this as the ratio of two variables: the price at which a car was actually sold; and the price at which an average car with similar observable characteristics was sold in that month in physical auctions. Autodaq provided these estimates using as a complete data set of physical auction sales.

\footnotetext{
${ }^{22}$ None of our results are sensitive to including those cars as not sold.

${ }^{23}$ This constraint was lifted later in the sample, but to little effect: only six cars were sold after three cycles.
} 
While being able to match these prices generates rich information, the inferences we can draw from the matches are limited, because the matches are not as precise as we would wish. In particular, the algorithm takes into account motorization, drive ( 2 wheel, four wheel), style, model, model-year but does not differentiate the matches by mileage and option data. For this reason, part of our analysis also relies for on the wholesale Kelly Blue Book (KBB) prices of the cars in the sample. The KBB is an industry guide meant to give wholesale and retail prices for vehicles. The KBB price specs out the full physical observable characteristics of the car (Year, Make, Model, Series, Engine, Drive-train, Options, Mileage, etc.). We do not use the KBB for any analysis of price levels, but only for our analysis of the changes in relative prices as a response to changes in the physical characteristics of the cars.

Descriptive statistics for our sample are given in table 3. It shows that of 3552 cars offered for sale on the Internet, $24.3 \%$ were sold over the period, at an average sell price of roughly $\$ 13,600$. Estimated physical auction values for the cars were available for a subsample of 3001 observations. The average physical auction value for these cars was $\$ 14,200$. The average ratio of Internet price to physical auction price, however, was 1.04 .

The average Kelly blue book value for these cars was substantially higher at $\$ 15,520$. According to Autodaq and the industry sources we spoke to (including one competitor), the roughly $10 \%$ differential is an industry standard. ${ }^{24}$

Table 4 presents all the unconditional pairwise correlations between the variables in the sample and foreshadows some of the results we are going to study in what follows.

\section{Empirical Strategy}


Our main objective is to use the data to measure the importance of informational asymmetries in Internet auctions. We try to do this using three elements in our data: the difference in price levels between the Internet and the physical world, the structure of relative prices, and the actual probability of sale of individual cars on the Internet. We expand on our use of these three pieces of information below.

\section{i. $\quad$ Relative Price Levels}

Assuming that the physical and electronic markets are competitive, we expect to see lower prices relative to the physical market when the quality of the cars sold on the Internet is worse than the quality of the cars sold in the physical real world. We can directly test this implication by comparing the average prices attained by the auctioned cars in the Internet market with the average price they would have attained had they been auctioned in the physical market.

There are two caveats to this interpretation. First, the price in the physical market is for an average car within a model-year-motorization-drivetrain cell. A finding that the average price of a car in the Internet is lower than in the physical market is compatible with no adverse selection, if cars in the Internet have more mileage for a given number of years driven, or if they have less options. Such differences would lead to lower average prices in the Internet, even in the absence of differences in the unobservable condition of the cars. Regrettably, the microdata on the physical market does not allow us to draw such distinctions. ${ }^{25}$

Second, the differences in average prices may respond to factors other than the average quality of the car sold. In particular, given the lower transaction costs attainable through the

\footnotetext{
${ }^{24}$ This difference between book value and selling price, and of a similar order of magnitude, is also present in Genesove's (1993) study. He finds that the book value is an imperfect predictor of the selling price, but does not document any systematic relation between the bias and the age, mileage or other characteristics of the car.
} 
Internet, dealers may be willing to pay higher prices for Internet-based transactions. For this reason, we think the evidence on the structure of relative prices in both markets is a better gauge of the extent to which adverse selection matters. We turn to this issue next.

\section{ii. $\quad$ Relative Price Structure}

As the model above shows, adverse selection between the physical market and the Internet is more likely to be a problem the higher the proportion of lemons and the lower their value. This implies that, if adverse selection is an important factor, it should manifest itself in a larger decrease in the Internet price than in the physical world price as the variance of the condition of the cars increases. In particular, conditional on the model motorization, etc., the variance of the value of a new car, of a car with low mileage or of one with a good observable condition is likely to be small, while that of an older car, or one with more miles will vary more depending on the care taken by its user. In other words, if the quality of care can only be (partially) gauged from direct observation of the car, the cars in the second category, for which care is likely to matter more, will be subject to relatively more important adverse selection problems over the Internet.

To test this hypothesis, we could turn again to the most direct data available, i.e. the price in the Internet relative to the price in the physical world. Because of the limitations in matching the Internet prices to the physical auction prices, we turn to the Kelly Blue Book prices as our proxy for the price that the car would have attained in a physical auction because these prices do differentiate cars by mileage, condition and options. As long as the relation between the KBB price and the price that an average car with the same characteristics would have obtained in the

\footnotetext{
${ }^{25}$ On the other hand, it could be expected that observable and unobservable differences in car condition move in the same direction.
} 
physical auction is constant, this is an appropriate proxy for our purposes. ${ }^{26}$ Using the ratio of the Internet prices to Kelly Blue Book prices, we test the hypothesis that as the variance in the condition of the car increases - as proxied by mileage, age and damages suffered by the car - the Internet price relative to the physical price decreases.

In testing these hypotheses, it is important to recognize that the observed price in the Internet auction is a censored variable. This is true because when the price that bidders in the Internet auction are willing to pay is not high enough, a car is not sold. In this case, the reservation price published by the seller is an upper bound on the valuation by buyers of the cars (or expected quality of the car), and as such can be used in a censored regression model. Thus we conduct the analysis first conditionally on sale, and then unconditionally, using a censored regression model.

\section{iii. $\quad$ Probability of Sale}

A third set of hypothesis concerns the probability that a car is sold. This contains no information on the comparison of adverse selection in Internet relative to physical markets, but may contain some information on whether adverse selection exists at all. Clearly, adverse selection implies that cars with good unobservable condition should be relatively less likely to sell. For this difference to be translated into an actually lower probability of sale, however, it would be necessary that cars in relatively good unobservable condition do 'show-up' in the Internet market, even if with a higher reserve price, only to be later withdrawn from auction. In our data, it is possible to assume that sellers initially attempt to sell all cars that they are planning to sell in auction on the Internet. First, that is the arrangement between the firm in our study and

\footnotetext{
${ }^{26}$ Note that the use of the KBB rather than the average physical auction price biases the results in favor of finding that adverse selection is more pronounced in the Internet than in physical markets. This is true because more
} 
the sellers. Second, the sellers can choose a high reservation price for even their bestconditioned cars. As a result, there is at worst only a small opportunity cost of trying the Internet.

If this is the case, we expect to observe that the higher the expected incidence of adverse selection, as given by the variance in the condition of the car, the lower the probability that the auction is successful. Thus we expect cars with more miles, higher age, and a history of more accidents in the past, to present a lower probability of sale if adverse selection is important in the Internet. To restate the hypothesis, if adverse selection exists, it must be making particularly difficult the sale of cars for which their condition has a higher variance.

The alternative hypothesis is that adverse selection is not a particular problem in Internet markets. A reason for this Autodaq's case is that individual dealer sales over the Internet were limited and under stringent conditions. To the extent that such dealers are more likely to try to dump their lemons, it may actually be that the Autodaq market is more, rather than less, efficient than the physical auction market.

\section{iv. Identity of the Seller}

Most cars in the Autodaq auctions are sold by large leasing companies or rental car companies. For the last part of our sample period, however, individual dealers were allowed to sell cars on the Internet. Following Genosove (1993), we can exploit the difference in incentives between those three types of sellers (individual companies, leasing companies and rental car companies) to uncover evidence of adverse selection. In particular, we expect adverse selection to be less important for cars coming off lease than for both cars sold by individual dealers and for 
cars that have been owned by rental car companies (and that, as a consequence, have had a multitude of users).

In the case of individual dealers, we expect them to have a more important incentive and opportunity to check the quality of care and condition of each individual car and to select which type of car to sell on their lot and which one at an electronic auction. As a consequence, after controlling for physical characteristics of these cars, we expect the identity of the seller of the car to matter in a predictable matter: individual dealers should obtain lower prices for their cars, holding everything else equal.

The same should be true for cars sold by rental car companies: holding everything else constant, rental car company cars have been through many more users. Their unobservable quality should be lower and, as a consequence, their average price should be lower.

Note that, similarly to the previous test, this test does not allow us to compare adverse selection in the internet and physical markets, but only to examine the extent to which adverse selection exists in the used car market.

\section{Results \\ i. $\quad$ Price Levels}

Table 5 presents tests of the hypothesis that, for cars of all ages, the car attained a lower price over the Internet than it would have attained in the physical world. The table allows us to reject at the $95 \%$ confidence level this hypothesis; in fact, the data suggests that the price attained over the Internet is significantly higher than the price in the physical world. 
In interpreting this evidence, however, caution must be exercised. As we pointed out before, the matching of an Internet price with the price the car would have attained in the phyisical world is only done conditional on year of manufacture, drive train, motorization etc. It does not take into account the options installed in the car, nor its mileage. These two characteristics are observable to bidders. Thus the difference in prices could be consistent with adverse selection if cars sold over the Internet have more options or lower mileage than cars sold in the physical world. A second caution concerns the savings in transactions cost (such as time and transport) discussed previously in this paper, which could lead buyers to pay more for a given car even when its unobservable quality is worse. For these reasons, we turn to the relative price structure in both types of markets, the physical and the electronic one.

\section{ii. Relative Price Structure}

The second piece of evidence available on the performance of Internet auctions concerns the structure of transaction prices of the cars. We present two tables on these relative prices: the first table 6 presents the evidence for the OLS estimates on those cars that are actually sold. This is far from a random sample, since the willingness to pay of the buyers is censored by the reservation price, and we do not observe transaction prices for unsold cars. For this reason, table 7 repeats the analysis with a censored normal regression in which the reservation price is used as the censoring point.

Consider first the regressions conditional on sales in Table 6 . The data here presents mixed evidence on the existence of more adverse selection in the electronic auction than in the physical market. On the one hand, a damaged car does not lose significantly more value in the Internet than it would in the physical market; nor does a higher mileage appear to decrease the 
value of the car more in the Internet than in the physical market, holding the age of the car constant. On the other hand, it does appear that as the age of the car increases, it affects more the value of the car in the Internet than it does affect its value in a physical market, suggesting that this could be a mechanism through which adverse selection is observed.

Table 7 presents the same evidence on the full sample (i.e. not conditionally on the sale). The analysis here is a variant of a Tobit, in which the censoring points are given in each case by the reservation price of the car. The evidence in favor of adverse selection in this table is, if anything, weaker: neither the damages of the car, not the age nor the mileage appear to reduce more the price that a car could attain on the Internet than the price that it would attain in a physical world auction.

\section{iii. $\quad$ Probability of Sale}

Table 8 presents the analysis of the probability that a sale actually takes place using a Probit model. The evidence is inconsistent with the existence of important adverse selection in these markets. Damaged cars do seem to be somewhat less likely to be sold, but neither older cars not cars with more miles are less likely to be transacted. In fact, there is a significantly positive effect of the mileage of the car and of its age on the probability of a sale.

Caution must also be exercised in interpreting these results. Only if dealers do not withdraw their 'good condition' cars prior to sale, but rather post them with a higher reservation price, do we expect to see adverse selection manifested in a lower probability of sale for cars more affected by adverse selection.

\section{iv. Identity of the Seller}


The last test for adverse selection we undertake centers on the relationship between the identity of the seller and the quality of the car bought. If, as argued in the previous section, the Internet involves more important informational asymmetries, we expect individual dealers and rental car companies to profit from these asymmetries by being more likely to sell undesirable cars than large leasing companies (who are more likely to simply want to sell all cars coming off-lease as efficiently as possible).

Table 9 tests these hypotheses. The table shows that we can clearly reject the hypothesis that individual dealers are perceived to sell lower quality cars over the internet than institutional ones. The first row controls only for the book price of the car, and shows a significant effect of individual dealer on price, but exactly of the opposite sign as the one predicted by the theory. The second row controls for Autodaq's 'reputation' by including a variable measuring the time Autodaq has been in operation. Controlling for this reputation, shows that a large part of the effect of individual dealers on selling price is due to the fact that prices are growing over time and dealers have only recently starting selling.

The lack of evidence of adverse selection in the dealer market is important for another reason. One might argue that our results for lessor or fleet sales are biased because (1) the buyers know the identity of the sellers and (2) lessor sellers get good prices for their cars in general. The similar results for the dealer market suggest that our results are not biased for this reason.

On the other hand, consistent with the adverse selection hypothesis, cars sold by rental companies obtain a lower price (holding observable characteristics equal).

v. Conclusions: Is Adverse Selection a problem over the Internet? 
Overall, we find little evidence consistent with the hypothesis that adverse selection is more pervasive in the electronic market than in the physical world, or even that adverse selection is a problem at all in the electronic marketplace we study. ${ }^{27}$ As we observed before, this conclusion necessarily must be qualified by the measures that Autodaq has taken to reduce the incidence of adverse selection in this particular instance.

\section{Nutrabid}

NutraBid provides technology infrastructure and eCommerce services to the nutraceutical industry. The nutraceutical industry consists of dietary supplements (vitamins, minerals, etc.), functional / medical foods, and natural / organic food and personal care. NutraBid is a neutral hub that performs a number of services including acting as a biased reverse auctioneer - for manufacturers buying from suppliers - and as an unbiased aggregator - for retailers buying from distributors and manufacturers. For NutraBid, we have data on its reverse auctioneer functionality.

\section{A. Process Improvements}

The procurement process for nutraceuticals consists of three phases both in the physical world and on the Internet. First, the buyer develops a request for proposals (RFP) to be sent to suppliers, mails the RFP to the suppliers, and receives responses from interested suppliers. Second, the buyer analyzes the RFPs and chooses the more attractive suppliers with whom to negotiate. Finally, the buyer plans negotiations, schedules them, and conducts them.

\footnotetext{
${ }^{27}$ In turn, previous studies of physical motor vehicle market by Bond (1982) and Genesove (1993), have found little evidence of adverse selection in these markets.
} 
Table 10 reports the time involved in the physical and Internet processes. The physical process takes 84 days which the NutraBid / Internet process takes only 28 days. NutraBid attributes the time savings to the following factors. In the first, RFP development phase, NutraBid believes that RFP development time is reduced by customizing standardized RFPs, using web-based RFPs and emailing RFPs and responses. In the second, RFP analysis phase, NutraBid believes it simplifies the analysis by focusing primarily on quality and services while ignoring pricing analysis to the auction. Finally, in the negotiation phase, the electronic auction precludes multiple rounds of face-to-face negotiations. NutraBid believes that a 10 minute electronic auction achieves a result that is equivalent to 3 or 4 rounds of face-to-face negotiations. This represents the largest savings in time.

We stress that the information in table 9 was provided by Nutrabid and we have not tried to confirm it with outside sources. We include it here as another indication that process improvements are potentially large.

\section{B. $\quad$ Marketplace Benefits}

NutraBid provided us with detailed results of their first reverse auction. The buyer provided NutraBid with desired purchases of more than 10 raw materials and the prices that the buyer was currently paying and expected to continue paying for those raw materials. The buyer also indicated the suppliers it wished to source from. NutraBid contacted those suppliers and then conducted a reverse auction for the desired amounts of the indicated raw materials.

Overall, the buyer obtained bids that were $14 \%$ lower in aggregate than the prices the buyer was currently paying. The buyer received lower bids on more than $80 \%$ of the individual 
raw materials offered. Nutrabid reports that is obtained similar savings in subsequent reverse auctions.

This result is clearly consistent with substantial marketplace benefits. Those benefits are potentially a result of lower search costs and better matching. However, as we noted earlier, the results also are consistent with two other explanations. First, it is possible that the lower prices represent reductions in seller processing costs. This would be consistent with the reduced process time analyzed in the previous section. Second, lower prices may partially represent a reallocation of the surplus of the transaction. I.e., the buyer is appropriating some of the oligopoly or other rents of the suppliers.

\section{Conclusion}

In this paper, we have studied changes in transaction costs from B2B e-commerce. We began with a conceptual framework to organize the transaction costs gains and losses that are likely to result when a transaction is transferred from a physical marketplace to an Internet-based one. Following Milgrom and Roberts (1992), we differentiated between the impact on coordination costs and motivation costs. We argued that it is likely that B2B e-commerce reduces coordination costs / increase efficiency. We classified these efficiencies into three broad categories - (1) process improvements; (2) marketplace benefits; and (3) indirect improvements. At the same time, B2B e-commerce affects motivation costs. In particular, we discuss the impact of the introduction of e-commerce on informational asymmetries.

We then used detailed internal data from one Internet-based firm, Autodaq, to measure process improvements, marketplace benefits, and motivation costs. We presented less detailed data and analyses for one other firm. Our results suggest that process improvements and 
marketplace benefits are potentially large. For the one company we study in detail, we do not find evidence that the Internet increases adverse selection costs. We suspect that this is at least due in part to the measures taken by Autodaq to avoid this problem.

Two important issues are left for future research. First, we have not found a way to study a final potential source of changes in transaction costs: commitment problems on the Internet. B2B e-commerce has the potential both to increase or decrease the ability of buyers and sellers to commit to transactions. First, by standardizing processes and by leaving an electronic trail, the Internet has the potential to increase the ability to commit (and, therefore, reduce the costs of imperfect commitment). Alternatively, a buyer may avoid intermediary fees by viewing the product over the Internet, but contacting the seller directly. As long as buyers cannot commit exante to buying from the internet, this commitment problem may result in markets with potential efficiency gains not succeeding.

A second issue that future research must consider concerns the consequences of these cost changes for the behavior of agents - what we have previously called indirect efficiencies. In particular, it remains an open question as to the effects of Internet markets on vertical integration in 'bricks and mortar' companies. 


\section{References}

Akerlof, George (1970). “The Market for 'Lemons': Quality Uncertainty and the Market Mechanism,” Quarterly Journal of Economics 222: 488-500.

Anderson, Erin (1985) "The Salesperson as Outside Agent or Employee: A Transaction Cost Analysis" Management Science 4 (Summer 1985), 234-54.

Bond, Eric W. (1982)“A Direct Test of the "Lemons” Model: The Market for Used Pick-Up Trucks” AER 72 (4): $832-80$

Coase, Ronald H. (1939). "The Nature of the Firm” Economica, 4:386-405.

Crocker Keith J. and Masten, Scott, E (1985). "Efficient Adaptation in Long-Term Contracts: Take or Pay Provisions in Natural Gas" American Economic Review 73:1083-1093.

Genesove, David (1993). “Adverse Selection in the Wholesale Used Car Market” JPE v101, n4: 644-65

Goldberg, Victor P. John R. and Erickson (1987): “Quantity and Price Adjustment in Long-term Contracts: A Case Study of Petroleum Coke"Journal of Law and Economics v30, n2: 369-98.

Holmstrom Bengt and Paul Milgrom (1991) "Multi-task principal-agent analyses: Linear contracts, asset ownership and job design", Journal of Law, Economics and Organization

Joskow, Paul A. (1985) "Vetical Integration and Long Term Contracts: The Case of Coal Burning Electric Generating Plants." Journal of Law, Economics and Organization, 1(1):33-80.

Kaplan, Steven and Mohan Sawhney (2000), “E-Hubs: The New B2B Marketplaces,” Harvard Business Review, May-June.

Lafontaine, Francine (1992), “Agency Theory and Franchising: Some Empirical Results,” Rand Journal Economics, 23: $263-283$.

Lafontaine, Francine, and Margaret E. SLADE (1998), “Incentive Contracting and the Franchise Decision,” NBER Working Paper 6544.

Lucking-Reiley, David and Daniel Spulber, "Business-to-Business Electronic Commerce,” Journal of Economic Perspectives, forthcoming.

Lyons, Bruce R (1994) “Contracts and Specific Investment: An Empirical Test of Transaction Cost Theory," Journal of Economics and Management Strategy v3, n2: 257-78

Milgrom Paul and John Roberts (1992). Economics, Organization and Management. Englewood Cliffs, NJ: Prentice Hall.

Phillips, Charles and Mary Meeker, “The B2B Internet Report: Collaborative Commerce,” Morgan Stanley Dean Witter Equity Research, April 2000.

Reekie, Duncan W. "South African Competition Law and the Diamond "Cartel." South African Journal of Economic and Management Sciences, N.S. v2, n2 (June 1999): 292-307

Sawhney, Mohan and Steven N. Kaplan, (1999 ) “Let’s Get Vertical,” Business 2.0, September.

Schwartz, Robert, David Gremmels and Kevin McGuire, “Commercetone,” Thomas Weisel Partners, June 2000.

Williamson, Oliver. (1985) “The Economic Institutions of Capitalism” New York: Free Press. 
Table 1

Process Cost Of Physical Auction Versus Internet Auction Process Per Car

Process cost of physical auction versus Internet auction based on used car auctions from October 1999 to September 2000.

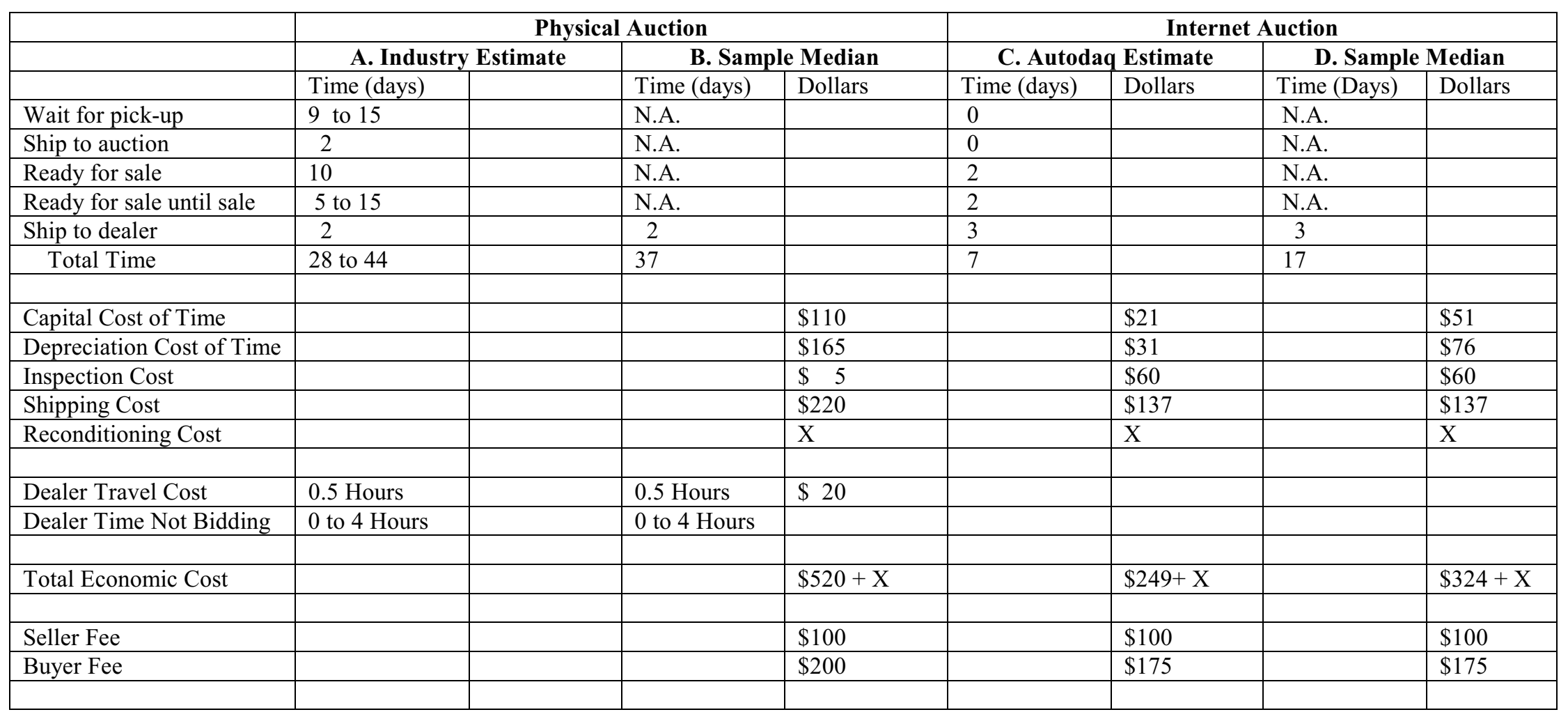

Assumptions:

Industry estimates for physical auction (panel A) were obtained from Tom Kontos at ADT Automotive and confirmed by other sources. Sample median for physical auction (panel B) is time from inspection to time of sale for 9205 cars sold by lessors through physical auction process. Augmented by two days for dealer shipment. Autodaq estimate for Internet Auction (panel C) were provided by Autodaq. Sample median for Internet Auction (panel D) is time from inspection to time of sale for 694 cars sold through Autodaq Internet process augmented by 3 days.

Wait for pick-up is time from lessee delivery of car to dealer until car is picked-up by physical auction.

Ready for sale is time from delivery at physical auction site to the time car is ready for sale. Includes time to recondition. 


\section{Table 1 (continued) \\ Process Cost Of Physical Auction Versus Internet Auction Process Per Car}

Used cars in our sample have an average sale value of $\$ 13,600$. Interest rate / cost of capital assumed to equal $8 \%$. Each day, therefore, costs seller $8 \% \mathrm{x}$ $\$ 13,600 / 365=\$ 2.98$ per day in capital costs.

Used car values in our sample decline or depreciate in value by $12 \%$ per year. Each day, therefore, costs seller $12 \% \mathrm{x} \$ 13,600 / 365=\$ 4.47$ per day in depreciation costs / forgone sales price. Based on estimates from pricing regressions.

Inspection cost for physical auction assumes 15 minutes at a cost of $\$ 20$ per hour; for Autodaq, is the cost to Autodaq.

Dealer travel cost assumes that dealer travels a total of two hours and buys four cars for an average of 0.5 hours per car. Dealer time is valued at $\$ 40$ per hour.

Shipping cost is two shipments at $\$ 110$ each for the physical auction; one shipment at $\$ 137$ for the Autodaq process. Based on Autodaq and industry interviews.

Reconditioning costs assumed to be the same for both processes. 


\section{Table 2}

Transport Costs Incurred by Buyers

Transport costs incurred by buyers in Autodaq Internet auctions between October 1999 and February 2000. Transport costs are actual transportation costs paid by purhcasers. Estimated transportation cost in physical auction provided by Autodaq.com and corroborated by interviews with industry participants.

\begin{tabular}{ll}
\hline & Transport Cost \\
\hline Cars transported from outside of California in Autodaq Auction & $\$ 465$ \\
Cars transported within California in Autodaq Auction & $\$ 223$ \\
Difference & $\$ 242$ \\
& \\
Estimated Transport Cost in Physical Auction & $\$ 110$ \\
\hline
\end{tabular}


Table 3

Descriptive Statistics

Descriptive statistics for Autodaq Internet auctions between October 1999 and October 2000. Sold equals one if a car put up for sale in an Autodaq auction was sold. Internet price is the price the car sold for in the Internet auction. Estimated physical auction value is the value the Autodaq estimates the car would have sold for in a physical auction based on data from physical auctions. Book price is the price of a similar car according to the Kelly Blue Book.

\begin{tabular}{llllll}
\hline Variable & Obs & Mean & Std. Dev. & Min & Max \\
\hline Sold & 3552 & 0.24 & 0.43 & 0.00 & 1.00 \\
Internet Price [\$1000] & 865 & 13.6 & 5.3 & 3.1 & 32.7 \\
Estimated Physical Auction Value[\$1000] & 3001 & 14.2 & 5.6 & 0.0 & 74.9 \\
Mileage (1000) & 3552 & 3.57 & 1.43 & 196.00 & 10.83 \\
Age (2000-year) & 3552 & 2.15 & 1.50 & 0.00 & 7.00 \\
Dollar of damages (1000\$) & 3552 & 0.128 & 0.20 & 0.00 & 2.22 \\
Internet to Physical Auction Price Ratio & 616 & 1.04 & 0.13 & 0.67 & 2.10 \\
Internet Price to Book (physical) & 843 & 0.88 & 0.08 & 0.61 & 1.40 \\
\hline
\end{tabular}


Table 4

\section{Correlation Matrix}

Correlation matrix for Autodaq Internet auctions between October 1999 and October 2000. Sold equals one if a car put up for sale in an Autodaq auction was sold. Internet price is the price the car sold for. Estimated physical auction value is the value the Autodaq estimates the car would have sold for in a physical auction based on data from physical auctions. Book price is the price of a similar car according to the Kelly Blue Book.

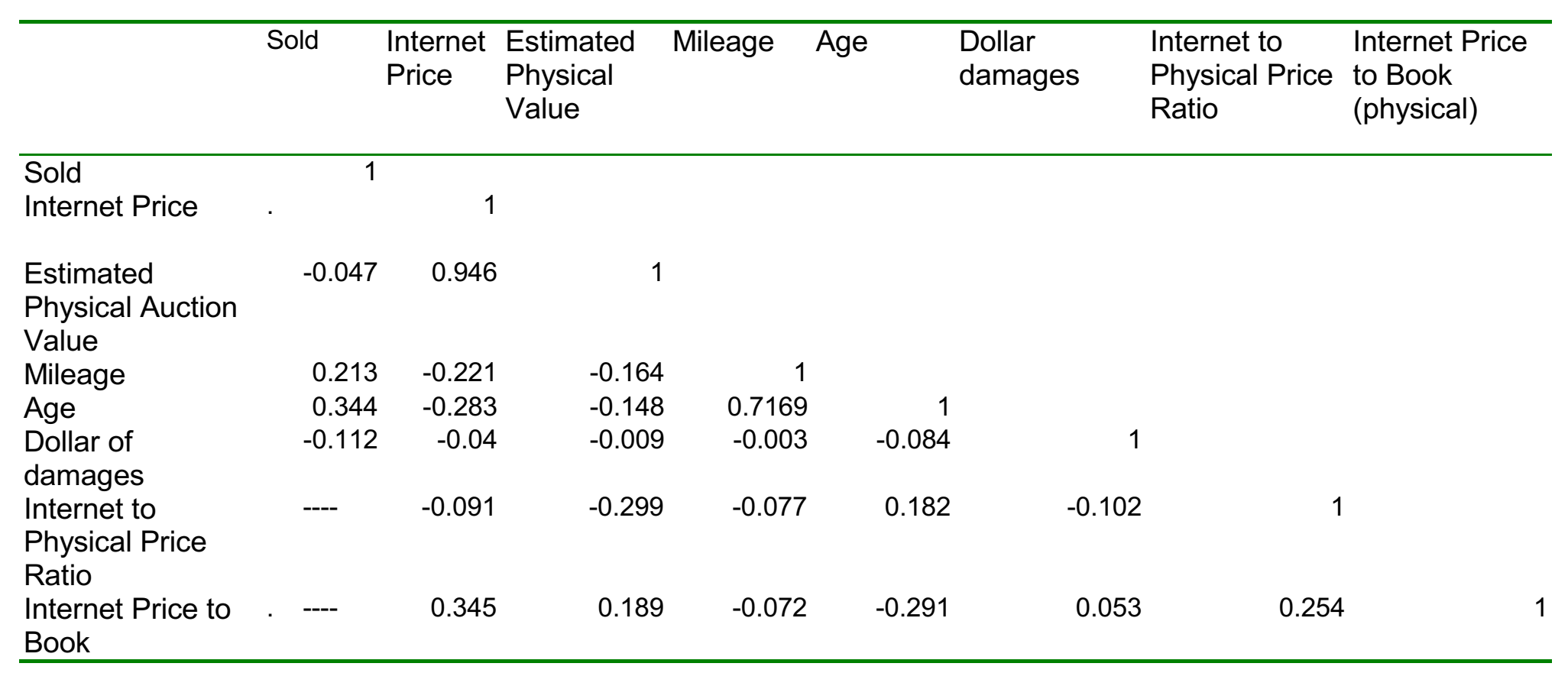


Table 5

\section{Price Levels: Internet Auctions Versus Physical Auctions}

Price level of internet auction relative to physical auctions Autodaq Internet auctions between October 1999 and October 2000. Internet price is the price the car sold for. In the Autodaq auction. Estimated physical auction value is the value the Autodaq estimates the car would have sold for in a physical auction based on data from physical auctions. The data correspond to a matched sample of internet sales with the price of an average car of identical model year, motorization and drive in physical auctions. ** is significantly larger than 1.

\begin{tabular}{|c|c|c|c|c|}
\hline $\begin{array}{l}\text { Model Year of } \\
\text { Manufacture }\end{array}$ & $\begin{array}{c}\text { Internet price/ } \\
\text { physical auction } \\
\text { value }\end{array}$ & $\begin{array}{l}\mathrm{N} \text { (number of } \\
\text { Internet Cars) }\end{array}$ & $95 \%$ Confidence & Interval \\
\hline 1995 & $\begin{array}{l}1.176^{\star *} \\
(0.035)\end{array}$ & 31 & 1.104 & 1.247 \\
\hline 1996 & $\begin{array}{l}1.114^{* *} \\
(0.022)\end{array}$ & 80 & 1.07 & 1.158 \\
\hline 1997 & $\begin{array}{l}1.018^{\star *} \\
(0.005)\end{array}$ & 418 & 1.008 & 1.028 \\
\hline 1998 & $\begin{array}{l}1.049 * * \\
(0.014)\end{array}$ & 42 & 1.02 & 1.078 \\
\hline 1999 & $\begin{array}{l}1.062^{* *} \\
(0.021)\end{array}$ & 23 & 1.019 & 1.105 \\
\hline
\end{tabular}


Table 6

\section{Price Structure: Internet Versus Physical World}

Regressions of Internet Price to Book Price on mileage, damages, age, auction date for Autodaq Internet auctions between October 1999 and October 2000. Internet price is the price the car sold for. Book price is the price of a similar car according to the Kelly Blue Book.

Dependent Variable is Internet Price to Book Price

\begin{tabular}{|c|c|c|c|c|c|c|c|}
\hline & \multicolumn{7}{|c|}{ Independent Variables } \\
\hline & $\begin{array}{l}\text { Mileage } \\
(000)\end{array}$ & $\begin{array}{c}\text { Damages } \\
(\$ 1000)\end{array}$ & Age & $\begin{array}{l}\text { Auction } \\
\text { Date }\end{array}$ & $\begin{array}{l}\text { Seller } \\
\text { Fixed } \\
\text { Effect }\end{array}$ & intercept & $\stackrel{\mathrm{N}}{\text { (R Square) }}$ \\
\hline (1) & $\begin{array}{c}-0.0042^{* *} \\
(0.002)\end{array}$ & & & & & $\begin{array}{l}0.8945^{\star *} \\
(0.0087)\end{array}$ & 843 \\
\hline (2) & & $\begin{array}{l}0.0228^{*} \\
(0.0148)\end{array}$ & & & & $\begin{array}{l}0.8753^{* *} \\
(0.0029)\end{array}$ & 843 \\
\hline (3) & & & $\begin{array}{c}-0.0229^{* *} \\
(0.0026)\end{array}$ & & & $\begin{array}{l}0.9483^{* *} \\
(0.0085)\end{array}$ & 843 \\
\hline$(4)$ & & & & $\begin{array}{c}0.0003^{* *} \\
(0)\end{array}$ & & $\begin{array}{l}0.8391^{* *} \\
(0.0042)\end{array}$ & 843 \\
\hline (5) & $\begin{array}{c}-0.0042^{* *} \\
(0.002)\end{array}$ & $\begin{array}{c}0.0226^{*} \\
(0.0148)\end{array}$ & & & & $\begin{array}{l}0.8926^{* *} \\
(0.0088)\end{array}$ & 843 \\
\hline (6) & $\begin{array}{c}0.008^{* *} \\
(0.0023)\end{array}$ & & $\begin{array}{c}-0.0291^{* *} \\
(0.0031)\end{array}$ & & & $\begin{array}{l}0.9343^{* *} \\
(0.0093)\end{array}$ & 843 \\
\hline (7) & $\begin{array}{l}0.0079^{* *} \\
(0.0023)\end{array}$ & $\begin{array}{c}0.0085 \\
(0.0142)\end{array}$ & $\begin{array}{c}-0.0289^{* *} \\
(0.0032)\end{array}$ & & & $\begin{array}{l}0.9333^{* *} \\
(0.0095)\end{array}$ & 843 \\
\hline (8) & $\begin{array}{l}0.0064^{* *} \\
(0.0023)\end{array}$ & $\begin{array}{c}0.0004 \\
(0.0138)\end{array}$ & $\begin{array}{c}-0.0187^{* *} \\
(0.0033)\end{array}$ & $\begin{array}{c}0.0002^{* *} \\
(0)\end{array}$ & & $\begin{array}{l}0.8795^{\star *} \\
(0.0115)\end{array}$ & 843 \\
\hline (9) & $\begin{array}{l}0.0078^{* *} \\
(0.0023)\end{array}$ & $\begin{array}{c}0.0103 \\
(0.0142)\end{array}$ & $\begin{array}{c}-0.0244^{* *} \\
(0.0036)\end{array}$ & $\begin{array}{l}0.0001^{*} \\
(0.0001)\end{array}$ & Yes & $\begin{array}{l}0.9256^{* *} \\
(0.0185)\end{array}$ & 843 \\
\hline
\end{tabular}

* Significant at 10\% level; ** Significant at 1\% level. 


\section{Table 7}

\section{Price Structure: Internet Versus Physical World}

Censored regressions of Internet Price to Book Price on mileage, damages, age, auction date for Autodaq Internet auctions between October 1999 and October 2000. Internet price is the price the car sold for. Book price is the price of a similar car according to the Kelly Blue Book.

Dependent Variable is Internet Price to Book Price

(Censored Normal MLE Estimates)

\begin{tabular}{|c|c|c|c|c|c|c|c|}
\hline & \multicolumn{7}{|c|}{ Independent Variables } \\
\hline & $\begin{array}{c}\text { Mileage } \\
(000)\end{array}$ & Damages & Age & $\begin{array}{l}\text { Auction } \\
\text { Date }\end{array}$ & $\begin{array}{l}\text { Seller } \\
\text { Fixed } \\
\text { Effect }\end{array}$ & intercept & $\mathrm{N}$ \\
\hline (1) & $\begin{array}{l}0.0094^{* *} \\
(0.0023)\end{array}$ & & & & & $\begin{array}{c}0.774^{* *} \\
(0.0099)\end{array}$ & 3147 \\
\hline (2) & & $\begin{array}{l}-0.0615^{\star *} \\
(0.0161)\end{array}$ & & & & $\begin{array}{c}0.8175^{\star *} \\
(0.004)\end{array}$ & 3147 \\
\hline (3) & & & $\begin{array}{l}0.0254^{* *} \\
(0.0027)\end{array}$ & & & $\begin{array}{l}0.7424^{* *} \\
(0.0086)\end{array}$ & 3147 \\
\hline (4) & & & & $\begin{array}{c}-0.0001^{* *} \\
(0)\end{array}$ & & $\begin{array}{l}0.8233^{* *} \\
(0.0062)\end{array}$ & 3147 \\
\hline (5) & $\begin{array}{l}0.0093^{* *} \\
(0.0023)\end{array}$ & $\begin{array}{l}-0.0617^{* *} \\
(0.0162)\end{array}$ & & & & $\begin{array}{c}0.7805^{\star *} \\
(0.01)\end{array}$ & 3147 \\
\hline (6) & $\begin{array}{c}-0.0103^{* *} \\
(0.0031)\end{array}$ & & $\begin{array}{l}0.0329 * * \\
(0.0035)\end{array}$ & & & $\begin{array}{c}0.763^{* *} \\
(0.0104)\end{array}$ & 3147 \\
\hline (7) & $\begin{array}{c}-0.0097^{* *} \\
(0.0031)\end{array}$ & $\begin{array}{l}-0.0448^{* *} \\
(0.0163)\end{array}$ & $\begin{array}{l}0.0319^{* *} \\
(0.0035)\end{array}$ & & & $\begin{array}{c}0.768^{* *} \\
(0.0105)\end{array}$ & 3147 \\
\hline (8) & $\begin{array}{l}-0.012^{\star *} \\
(0.0031)\end{array}$ & $\begin{array}{l}-0.0521^{* *} \\
(0.0162)\end{array}$ & $\begin{array}{c}0.0418^{* *} \\
(0.004)\end{array}$ & $\begin{array}{c}0.0002^{* *} \\
(0)\end{array}$ & & $\begin{array}{l}0.7199^{* *} \\
(0.0143)\end{array}$ & 3147 \\
\hline (9) & $\begin{array}{r}-0.0036 \\
(0.003)\end{array}$ & $\begin{array}{l}-0.036^{\star *} \\
(0.0157)\end{array}$ & $\begin{array}{l}-0.0027 \\
(0.0047)\end{array}$ & $\begin{array}{c}0.0001 \\
(0.0001)\end{array}$ & Yes & $\begin{array}{c}0.872^{\star *} \\
(0.0259)\end{array}$ & 3147 \\
\hline
\end{tabular}

${ }^{*}$ Significant at $10 \%$ level; ${ }^{* *}$ Significant at $1 \%$ level. 


\section{Table 8 \\ Probability of Sale on Internet}

Probit regressions of the probability of a sale on the Internet as a function of mileage, damages, age, auction date for Autodaq Internet auctions between October 1999 and October 2000.

(Probit: Dependent Variable is 1 if auction successful)

\begin{tabular}{|c|c|c|c|c|c|c|c|}
\hline & \multicolumn{7}{|c|}{ Independent Variables } \\
\hline & $\begin{array}{l}\text { Mileage } \\
(000)\end{array}$ & Damages & Age & $\begin{array}{l}\text { Auction } \\
\text { Date }\end{array}$ & $\begin{array}{l}\text { Seller } \\
\text { Fixed } \\
\text { Effect }\end{array}$ & intercept & $\mathrm{N}$ \\
\hline (1) & $\begin{array}{c}0.207^{* *} \\
(0.0164)\end{array}$ & & & & & $\begin{array}{c}-1.4655^{* *} \\
(0.0664)\end{array}$ & 3552 \\
\hline (2) & & $\begin{array}{c}-0.0009^{* *} \\
(0.0001)\end{array}$ & & & & $\begin{array}{c}-0.6004^{* *} \\
(0.0266)\end{array}$ & 3552 \\
\hline (3) & & & $\begin{array}{l}0.3852^{* *} \\
(0.0193)\end{array}$ & & & $\begin{array}{c}-1.6448^{* *} \\
(0.0569)\end{array}$ & 3552 \\
\hline (4) & & & & $\begin{array}{c}-0.0044^{* *} \\
(0.0002)\end{array}$ & & $\begin{array}{l}0.1435^{\star *} \\
(0.0469)\end{array}$ & 3552 \\
\hline (5) & $\begin{array}{l}0.2057^{\star *} \\
(0.0164)\end{array}$ & $\begin{array}{c}-0.0009^{\star *} \\
(0.0001)\end{array}$ & & & & $\begin{array}{c}-1.3693^{\star *} \\
(0.068)\end{array}$ & 3552 \\
\hline (6) & $\begin{array}{c}-0.0728^{* *} \\
(0.0231)\end{array}$ & & $\begin{array}{l}0.4373^{* *} \\
(0.0255)\end{array}$ & & & $\begin{array}{c}-1.4998^{* *} \\
(0.0731)\end{array}$ & 3552 \\
\hline (7) & $\begin{array}{c}-0.0661^{* *} \\
(0.0231)\end{array}$ & $\begin{array}{c}-0.0006^{* *} \\
(0.0001)\end{array}$ & $\begin{array}{l}0.4262^{* *} \\
(0.0257)\end{array}$ & & & $\begin{array}{c}-1.4331^{* *} \\
(0.0743)\end{array}$ & 3552 \\
\hline (8) & $\begin{array}{c}-0.03 \\
(0.0238)\end{array}$ & $\begin{array}{c}-0.0005^{\star *} \\
(0.0001)\end{array}$ & $\begin{array}{l}0.2963^{* *} \\
(0.0308)\end{array}$ & $\begin{array}{c}-0.0022^{* *} \\
(0.0003)\end{array}$ & & $\begin{array}{c}-0.8456^{* *} \\
(0.1073)\end{array}$ & 3552 \\
\hline (9) & $\begin{array}{c}0.0066 \\
(0.0246)\end{array}$ & $\begin{array}{l}-0.0002^{*} \\
(0.0001)\end{array}$ & $\begin{array}{l}0.1734^{* *} \\
(0.0408)\end{array}$ & $\begin{array}{c}-0.0069^{* *} \\
(0.0007)\end{array}$ & Yes & $\begin{array}{c}0.539^{* *} \\
(0.2174)\end{array}$ & 3552 \\
\hline
\end{tabular}

${ }^{*}$ Significant at $10 \%$ level; ** Significant at $1 \%$ level. 


\section{Table 9}

\section{Effect of Seller Type on Price Paid over the Internet}

Regressions of Internet Price paid on seller type, bookprice, mileage, damages, age, and auction date for Autodaq Internet auctions between October 1999 and October 2000. Internet price is the price the car sold for. Book price is the price of a similar car according to the Kelly Blue Book.

(Dependent Variable is Internet Price actually Paid in \$1000s)

\begin{tabular}{|c|c|c|c|c|c|c|c|c|c|}
\hline & \multicolumn{9}{|c|}{ Independent Variables } \\
\hline & $\begin{array}{c}\text { Seller }= \\
\text { Individual } \\
\text { Dealer }\end{array}$ & $\begin{array}{c}\text { Seller }= \\
\text { Rental } \\
\text { Company }\end{array}$ & $\begin{array}{l}\text { Blue Book } \\
\text { Price }\end{array}$ & $\begin{array}{l}\text { Auction } \\
\text { Date }\end{array}$ & $\begin{array}{c}\text { Damages } \\
(\$ 000)\end{array}$ & $\begin{array}{l}\text { Auction } \\
\text { Date }\end{array}$ & $\begin{array}{c}\text { Mileage } \\
(000)\end{array}$ & Intercept & $\begin{array}{l}\mathrm{RSq} \\
(\mathrm{N})\end{array}$ \\
\hline (1) & $\begin{array}{c}0.9222^{* *} \\
(0.131)\end{array}$ & $\begin{array}{c}0.288^{*} \\
(0.2027)\end{array}$ & $\begin{array}{l}0.9112^{* *} \\
(0.0062)\end{array}$ & & & & & $\begin{array}{c}-0.5373^{* *} \\
(0.1045)\end{array}$ & $\begin{array}{c}0.9628 \\
(843)\end{array}$ \\
\hline (2) & $\begin{array}{c}0.2279 \\
(0.1761)\end{array}$ & $\begin{array}{c}-0.3181^{*} \\
(0.2249)\end{array}$ & $\begin{array}{l}0.9093^{* *} \\
(0.0061)\end{array}$ & $\begin{array}{c}0.003^{* *} \\
(0.0005)\end{array}$ & & & & $\begin{array}{c}-0.8438^{* *} \\
(0.1155)\end{array}$ & $\begin{array}{c}0.9642 \\
(843)\end{array}$ \\
\hline (3) & $\begin{array}{c}0.226 \\
(0.1814)\end{array}$ & $\begin{array}{c}-0.7787^{* *} \\
(0.2461)\end{array}$ & $\begin{array}{l}0.9022^{* *} \\
(0.0064)\end{array}$ & $\begin{array}{l}0.0023^{* *} \\
(0.0005)\end{array}$ & $\begin{array}{c}0.0113 \\
(0.2068)\end{array}$ & $\begin{array}{c}-0.2668^{* *} \\
(0.0537)\end{array}$ & $\begin{array}{l}0.0907^{* *} \\
(0.0325)\end{array}$ & $\begin{array}{l}-0.1766 \\
(0.2333)\end{array}$ & $\begin{array}{c}0.9652 \\
(843)\end{array}$ \\
\hline
\end{tabular}

${ }^{*}$ Significant at $10 \%$ level; ${ }^{* *}$ Significant at $1 \%$ level. 
TABLE 10

Process Cost Of Nutraceutical Procurement Process:

Physical / Existing Process Versus Nutrabid / Internet Process

\begin{tabular}{|c|c|c|}
\hline & Physical / Existing & Nutrabid / Internet \\
\hline & TIME (DAYS) & TIME (DAYS) \\
\hline $\begin{array}{l}\text { 1. Develop, Mail RFP to Suppliers and } \\
\text { Receive Responses }\end{array}$ & 21 & 14 \\
\hline 2. Analyze RFP, Screen Suppliers & 14 & 7 \\
\hline $\begin{array}{l}\text { 3. Plan Negotiations, Schedule, Conduct } \\
\text { 2-3 Rounds of Face to Face Negotiations }\end{array}$ & 49 & 7 \\
\hline Total & 84 & 28 \\
\hline
\end{tabular}

